\title{
Effect of oil concentration and residence time on the biodegradation of $\alpha$-pinene vapours in two-liquid phase suspended-growth bioreactors
}

\author{
María Montes, María C. Veiga, Christian Kennes \\ Journal of Biotechnology, Volume 157, Issue 4, 20 February 2012, Pages 554-563 \\ Special Issue: IBS2010 Part II (Biotechnology for a more sustainable environment \\ decontamination and energy production) \\ DOI: 10.1016/j.jbiotec.2011.07.019
}

\begin{abstract}
Recently, research on the use of binary aqueous-organic liquid phase systems for the treatment of polluted air has significantly increased. This paper reports the removal of $\alpha$-pinene from a waste air stream in a continuous stirred tank bioreactor (CSTB), using either a single-liquid aqueous phase or a mixed aqueous-organic liquid phase. The influence of gas flow rate, load and pollutant concentration was evaluated as well as the effect of the organic to aqueous phase ratio. Continuous experiments were carried out at different inlet $\alpha$-pinene concentrations, ranging between 0.03 and $25.1 \mathrm{~g} \mathrm{~m}^{-3}$ and at four different flow rates, corresponding to residence times (RTs) of $120 \mathrm{~s}, 60 \mathrm{~s}, 36 \mathrm{~s}$ and $26 \mathrm{~s}$. The maximum elimination capacities (ECs) reached in the CSTB were $382 \mathrm{~g} \mathrm{~m}^{-3} \mathrm{~h}^{-1}$ (without silicone oil) and $608 \mathrm{~g} \mathrm{~m}^{-3} \mathrm{~h}^{-1}$ (with $5 \% \mathrm{v} / \mathrm{v}$ silicone oil), corresponding to a 1.6-fold improvement using an aqueous-organic liquid phase. During shock-loads experiments, the performance and stability of the CSTB were enhanced with $5 \%$ silicone oil, quickly recovering almost $100 \%$ removal efficiency (RE), when pre-shock conditions were restored. The addition of silicone oil acted as a buffer for high $\alpha$-pinene loads, showing a more stable behaviour in the case of twoliquid-phase systems.
\end{abstract}

\section{Keywords}

a-Pinene; Biodegradation; Continuous stirred tank bioreactor; Rhodococcus erythropolis; Silicone oil; Two-phase partitioning bioreactor 


\section{Introduction}

$\alpha$-Pinene is a major VOC emitted, among others, by the pulp and paper industry and the forest products industry and, as a monoterpene, it can react in the atmosphere to form free radicals and deplete the ozone layer (Corchnoy and Atkinson, 1990). Bioprocesses are suitable for air pollution control over a wide range of air flow rates of up to more than $100,000 \mathrm{~m}^{3} \mathrm{~h}^{-1}$, containing relatively low pollutant concentrations (Kennes et al., 2009a). In such systems, pollutant elimination is the result of a complex combination of mass transfer, such as diffusion and convection, and biodegradation. Although the basic mechanisms for removal are similar for all reactor types (Boudreau and Daugulis, 2006), differences depend on the phases in which the microbial populations and pollutants are located. An emerging technology for the treatment of VOCs is the two phase-partitioning bioreactor (TPPB), also known as biphasic aqueous/organic reactor. Generally, TPPBs configurations consist of an aqueous phase, which contains the pollutant degrading microorganisms and the nutrients required to support their growth, and an immiscible, non-biodegradable and biocompatible organic liquid phase, which exhibits a high affinity for the hydrophobic target pollutants (Muñoz et al., 2006). The addition of an immiscible phase should represent an efficient alternative to reduce mass transfer limitations of poorly water-soluble compounds (Quijano et al., 2010). Nevertheless, some authors showed experimentally for several pollutants that mass transfer coefficients, measured as $\mathrm{K}_{\mathrm{L}} \mathrm{a}$, were not significantly different in water or in silicone, which was attributed to the higher viscosity of oil compared to water (Darracq et al., 2010a and Darracq et al., 2010b).

Although a large variety of bioreactor configurations has been used in waste gas treatment, the continuous stirred tank bioreactor (CSTB) is by far the most widely studied two-liquid phase system (Kennes et al., 2009a). Advantages of the CSTB are that they allow efficient control of environmental conditions, such as temperature and $\mathrm{pH}$, and prevent biomass overgrowth, channeling, shrinkage, drying, and deterioration of the filter bed structure (Muñoz et al., 2007), more typical of packed-bed bioreactors. Recently, it has been shown that the presence of an organic solvent decreases the volatile pollutants concentration in the suspended-growth water phase, so that microorganisms in the aqueous phase will not be inhibited (Muñoz et al., 2007 and Muñoz et al., 2008). It is usually accepted that the organic phase acts as a reservoir, protecting the microorganisms from the toxicity of the pollutant (Déziel et al., 1999 and Rene et al., 2011a).

The choice of the organic solvent is a critical aspect in two-liquid phase bioreactors. It has been demonstrated that the amount and the kind of solvent can modify mass transfer and degradation rates in the system (Déziel et al., 1999 and Marcoux et al., 2000). According to the literature data, the organic phase usually represents between 5 and $50 \%$ of the total liquid volume (Aldric and Thonart, 2008, Davidson and Daugulis, 2003a, Davidson and Daugulis, 2003b, Montes et al., 2010 and Muñoz et al., 2006). Polymeric solvents such as silicone oil can play a crucial role in key separation processes such as absorption of VOCs from contaminated air streams. Some reports have also suggested that solid polymers could play a similar role as liquid organic phases in TPPB (Montes et al., 2011). From a chemical engineering and thermodynamic point of view, silicone oil is still the most popular and most commonly used organic phase in lab-scale research because of its characteristics, in terms of biodegradability and biocompatibility (Kennes et al., 2009b). 
The main purpose of this study was to investigate the potential of biphasic reactors for the degradation of $\alpha$-pinene present in polluted air. The advantage of such systems for $\alpha$-pinene removal was recently shown in the case of biotrickling filters (Montes et al., 2010) and is illustrated here for the case of suspended-growth bioreactors. The study was performed in two parts: first, a single-liquid aqueous phase was used and secondly, a combination of an aqueous-organic liquid phase was used with organic to water phase ratios of either $2 \%$ or $5 \% v / v$. The effect of the inlet pollutant concentration and empty bed residence time (RT) on the performance of the bioreactor was investigated. The influence of the organic phase when applying shock-loads was studied as well.

\section{Materials and methods}

\subsection{Chemicals}

All chemicals were of analytical grade. Alpha-pinene, 98\% $\left(\mathrm{C}_{10} \mathrm{H}_{16}\right)$ and Silicone Oil DC 200 (polydimethylsiloxane $\left.\left(-\mathrm{Si}\left(\mathrm{CH}_{3}\right)_{2} \mathrm{O}-\right)_{n}\right)$ were purchased from Sigma-Aldrich Química, S.A., while the other chemicals used for this research were obtained from Panreac Química, S.A.

\subsection{Microorganism and growth conditions}

The CSTB was inoculated with a bacterial co-culture containing a Rhodococcus erythropolis DCL14 strain as well as another unidentified bacterium. In biofilters treating $\alpha$-pinene vapours, some of the commonly reported species belong to the genera Rhodococcus and this microorganism appeared to be able to mineralize gas-phase $\alpha$ pinene ( Langolf and Kleinheinz, 2006). Besides, some Rhodococcus spp. also have the ability to grow on terpenoids, including $\alpha$-pinene, using them as their sole carbon and energy source ( Hernandez et al., 1997). The bacterial culture used in the present study was grown and maintained on petri dishes at room temperature, in presence of $\alpha$-pinene vapours. The agar medium contained per litre distilled water: $15 \mathrm{~g}$ bacto-agar, $3.5 \mathrm{~g}$ yeast extract, $10 \mathrm{~mL}$ of a $100 \times$ concentrated medium and $10 \mathrm{~mL}$ of a $100 \times$ concentrated phosphate buffer solution. The medium contained per litre distilled water (adding chemicals in the order described): $1 \mathrm{~g}$ EDTA, $0.2 \mathrm{~g} \mathrm{ZnSO}_{4} \cdot 7 \mathrm{H}_{2} \mathrm{O}, 0.1 \mathrm{~g} \mathrm{CaCl}_{2} \cdot 2 \mathrm{H}_{2} \mathrm{O}$, $0.5 \mathrm{~g} \mathrm{FeSO}_{4} \cdot 7 \mathrm{H}_{2} \mathrm{O}, 0.02 \mathrm{~g} \mathrm{Na}_{2} \mathrm{MoO}_{4} \cdot 2 \mathrm{H}_{2} \mathrm{O}, 0.02 \mathrm{~g} \mathrm{CuSO}_{4} \cdot 5 \mathrm{H}_{2} \mathrm{O}, 0.04 \mathrm{~g} \mathrm{CoCl}_{2} \cdot 6$

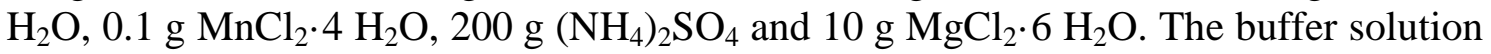
$(\mathrm{pH}=7)$ contained per $\mathrm{L}$ distilled water: $155 \mathrm{~g} \mathrm{~K}_{2} \mathrm{HPO}_{4}$ and $85 \mathrm{~g} \mathrm{NaH}_{2} \mathrm{PO}_{4} \cdot \mathrm{H}_{2} \mathrm{O}$. The medium was autoclaved at $120^{\circ} \mathrm{C}$ for $20 \mathrm{~min}$.

The liquid medium used for preparing the inoculum for the reactors had the same composition as the agar medium but with no bacto-agar and no yeast extract. For bioreactor experiments, $100 \mathrm{~mL}$ liquid medium was inoculated with the bacterial coculture and incubated for 5 days at $30^{\circ} \mathrm{C}$ and $170 \mathrm{rpm}$. The culture was then added to the reactor. Biomass samples were periodically collected from the bioreactor and examined under a phase-contrast optical microscope in order to confirm the presence of Rhodococcus spp. It was observed that, Rhodococcus-like bacteria were dominantly present in all these samples and were primarily responsible for all the $\alpha$-pinene degraded in the CSTB. 


\subsection{Experimental}

\subsubsection{Batch biodegradation experiments}

Batch experiments were used to determine the potential of $\alpha$-pinene degradation using the bacterial co-culture, either with or without silicone oil. Glass flasks of $110 \mathrm{~mL}$ were supplied with $9 \mathrm{~mL}$ of sterilized fresh mineral medium with yeast extract, $1 \mathrm{~mL}$ of a suspension of the co-culture mentioned above and $5 \mu \mathrm{L}$ liquid $\alpha$-pinene (initial mass $4.29 \mathrm{mg}$ ). Samples with silicone oil were also tested under similar conditions, using 5\% silicone oil and 95\% mineral medium. The flasks were closed with rubber stoppers and aluminium caps and were incubated at $30^{\circ} \mathrm{C}$ on a rotary shaker at $180 \mathrm{rpm}$. Each experiment was conducted in duplicate. The average values are presented in the results. The biodegradation profile was monitored by periodically withdrawing $2.5 \mathrm{~mL}$ of headspace samples and subjecting them to gas chromatograph analysis for residual $\alpha$-pinene concentration. Head-space samples were also withdrawn periodically for analyzing carbon dioxide generation during the biodegradation process. Optical density of the aqueous phase was measured at $600 \mathrm{~nm}$ to estimate biomass growth.

\subsubsection{Partition coefficient}

Batch partition coefficients tests were performed at $30^{\circ} \mathrm{C}$ with mixing on a rotary shaker at $180 \mathrm{rpm} .110 \mathrm{~mL}$ vials were filled with $45 \mathrm{~mL}$ each of water or silicone oil (viscosity: $10 \mathrm{mPa} \mathrm{s}, 25^{\circ} \mathrm{C}$ ). A known mass of $\alpha$-pinene was injected into the vials and left for $24 \mathrm{~h}$. The shake flasks were sealed with rubber stoppers. Duplicate samples were taken from each liquid phase, for each experiment done at different concentrations. After equilibrium was reached between the phases, the headspace $\alpha$-pinene concentration was measured by GC analysis (Bailón et al., 2009). The gas liquid partition coefficients $(P)$ used in this work are defined by Eq. (1).

$P=\frac{[\alpha \text {-pinene }]_{\text {Liquid }}}{[\alpha \text {-pinene }]_{\text {gas }}}$

where equilibrium $\alpha$-pinene concentrations in the liquid and the gas phase are represented. The oil/air and water/air partition coefficients were then obtained from the slope of the plot of the $\alpha$-pinene concentration in the oil or water phase vs the $\alpha$-pinene concentration in the gas phase.

\subsubsection{Influence of silicone oil}

Batch experiments were carried out in order to evaluate the uptake of biomass from the aqueous phase to the water/oil emulsion. The bacterial co-culture maintained on petri dishes was used for preparing the inoculum. It was kept in an Erlenmeyer flask containing a saline aqueous medium containing $\mathrm{NaCl}(0.9 \%)$. The flask was incubated in a rotary shaker, continuously shaken at $180 \mathrm{rpm}$. Successive additions of $\alpha$-pinene were carried out until reaching a constant optical density close to $0.7 .110 \mathrm{~mL}$ vials were filled with a total volume of $20 \mathrm{~mL}$, using the previous suspension and ratios of silicone oil to water between $10 \%$ and $50 \%$. A control flask was prepared and incubated under similar contitions without organic solvent in order to control any optical density variation. Shake flasks were sealed with rubber stoppers and kept at $30^{\circ} \mathrm{C}$ in an orbital shaker. Duplicate samples were prepared. Measurements of the optical density in the 
aqueous phase were carried out until silicone oil could not absorb more biomass from the aqueous phase, which means constant optical density.

\subsubsection{Continuous stirred tank bioreactor (CSTB)}

A general schematic of the CSTB system is shown in Fig. 1. The $3 \mathrm{~L} \mathrm{New} \mathrm{Brunswick}$ Scientific BioFlo 110 reactor was equipped, among others, with a PCU, a level control module, dissolved $\mathrm{O}_{2}$ and $\mathrm{pH}$ control modules. A water jacket allowed to maintain a constant temperature. The reactor was operated at a temperature of $25^{\circ} \mathrm{C}$, an agitation speed of $400 \mathrm{rpm}$ and with a total working volume of $1.5 \mathrm{~L}$. The $\mathrm{pH}$ of the culture was kept constant, at 7.0, by utilizing a $2 \mathrm{~N} \mathrm{NaOH}$ solution as neutralizing agent, automatically added by means of a peristaltic pump. The total reactor volume was maintained constant. Water evaporation losses in the reactor were rectified by the addition of fresh medium in order to maintain the working volume constant and to ensure that the system was not nutrient limited. The synthetic waste gas was generated by bubbling air through liquid $\alpha$-pinene (minor air stream) and mixing it with a large stream of clean compressed air in a mixing chamber before entering the system. The flow rates of both gas streams were measured and regulated with flowmeters (Mohammad et al., 2007). Gas was continuously flowing in and out of the reactor behaving as a CSTB. Variable gas-phase $\alpha$-pinene concentrations were obtained by changing the flow rate of the $\alpha$-pinene stream. At a given gas-flow rate, there was a continuous supply of mass, containing $\alpha$-pinene, into the system, and the non-treated air and the degradation end-products (mainly $\mathrm{CO}_{2}$ ) were continuously leaving the system. The removal of $\alpha$-pinene was investigated in different phases corresponding to decreasing residence times (RTs) of $120 \mathrm{~s}, 60 \mathrm{~s}, 36 \mathrm{~s}$ and $26 \mathrm{~s}$. The RT used in this study is defined as the ratio of the volume of medium inside the reactor to the gas-flow rate.

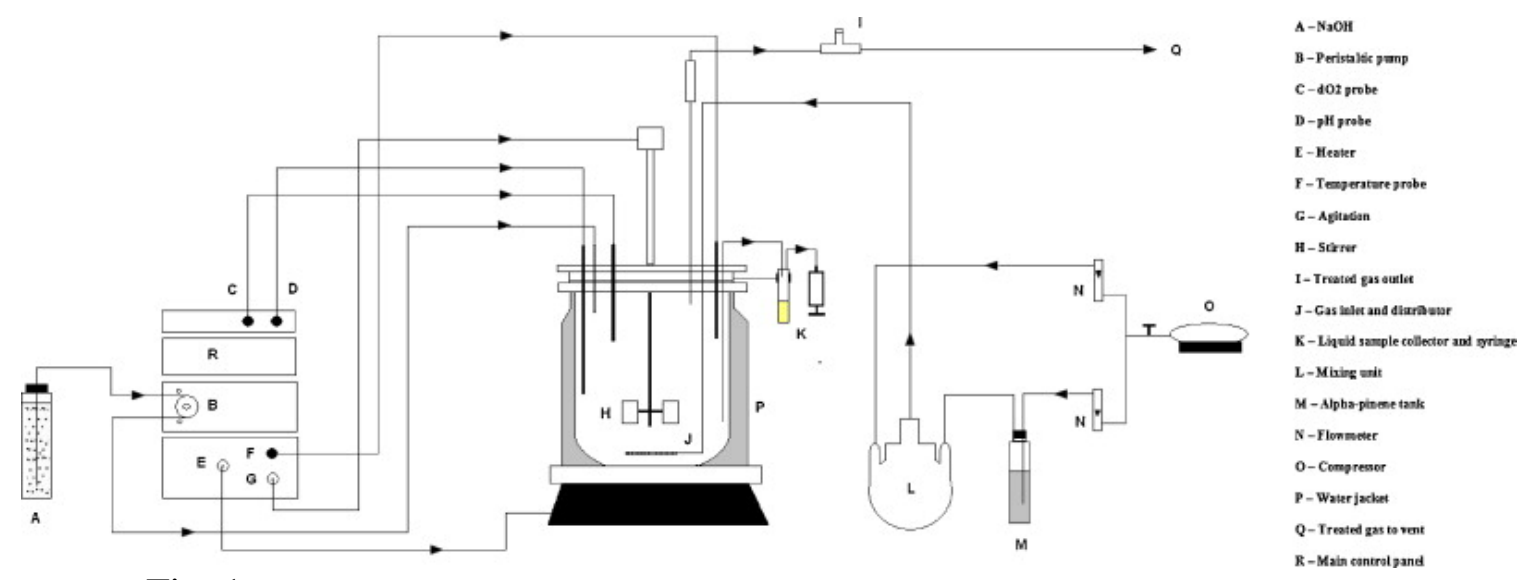

Fig. 1.

Schematic of the continuous stirred tank bioreactor.

The influence of the amount silicone oil on $\alpha$-pinene biodegradation was evaluated in the stirred tank bioreactor. The reactor was filled with two different silicone oil to water ratios of either $2 \% v / v(1.47 \mathrm{~L}$ aqueous mineral medium, $30 \mathrm{~mL}$ silicone oil) or $5 \% \mathrm{v} / \mathrm{v}$ (1.42 $\mathrm{L}$ aqueous mineral medium, $75 \mathrm{~mL}$ silicone oil), and inoculated with the bacterial co-culture to reach an initial biomass concentration of $0.5 \mathrm{~g} \mathrm{~L}^{-1}$. After each experiment the reactor was autoclaved and inoculated with fresh medium and fresh biomass. The reactor was operated under constant experimental conditions as described above $\left(25^{\circ} \mathrm{C}\right.$, 
$400 \mathrm{rpm}, \mathrm{pH} 7$ and total working volume of $1.5 \mathrm{~L}$ ). Besides, medium containing the microorganisms and silicone oil was removed periodically, in order to determine the proportion of silicone oil in the system. When a loss of silicone oil was noticed, the required volumes of silicone oil and fresh medium were added to the system.

\subsection{Analytical procedures}

Gas-phase concentrations of $\alpha$-pinene were measured on a Hewlett-Packard 6890 gas chromatograph equipped with a $50 \mathrm{~m}$ TRACER column (TR-WAX, internal diameter $0.32 \mathrm{~mm}$, film thickness $1.2 \mu \mathrm{m}$ ) and a flame ionization detector. The flow rates were $30 \mathrm{~mL} \mathrm{~min}^{-1}$ for $\mathrm{H}_{2}$ and $300 \mathrm{~mL} \mathrm{~min}^{-1}$ for air. Helium was used as the carrier gas at a flow rate of $2 \mathrm{~mL} \mathrm{~min}{ }^{-1}$. The temperatures at the GC injection, oven and detection ports were 250,120 and $250{ }^{\circ} \mathrm{C}$ respectively. Both the inlet and outlet streams were sampled. Unknown sample concentrations were determined from a calibration curve that was plotted based on peaks obtained from known concentrations of $\alpha$-pinene. Inlet and outlet gas samples were taken by means of a Terumo Gas Tight $2.5 \mathrm{~mL}$ syringe. Typical gas elution time in the GC was $3.8 \mathrm{~min}$ for $\alpha$-pinene. The detection limit for $\alpha$-pinene by GC corresponds to an $\alpha$-pinene concentration of $5.6 \mathrm{mg} \mathrm{m}^{-3}$. Similarly, carbon dioxide was analyzed on a HP 5890 gas chromatograph with a Porapak Q 80/100 (inox) column $\left(2 \mathrm{~m} \times 1 / 8^{\prime \prime}\right)$, equipped with a thermal conductivity detector (TCD). Helium was used as the carrier gas at a flow rate of $15 \mathrm{~mL} \mathrm{~min}^{-1}$. The $\mathrm{CO}_{2}$ concentration was determined at an injection temperature of $90^{\circ} \mathrm{C}$, an oven temperature of $25^{\circ} \mathrm{C}$, and with the TCD set at $100{ }^{\circ} \mathrm{C}$. The concentrations in the samples were determined from a calibration curve based on peaks obtained from known concentrations of $\mathrm{CO}_{2}$, by introducing known volumes of $\mathrm{CO}_{2}$ into a $1 \mathrm{~L}$ sealed Tedlar bag. Inlet and outlet gas samples were taken from the reactors by means of a Terumo insulin Gas Tight $1 \mathrm{~mL}$ syringe. Biomass concentration was measured at $600 \mathrm{~nm}$ with a Lambda $11 \mathrm{UV} / \mathrm{Vis}$ spectrophotometer, and a calibration curve was prepared to convert optical density (OD) into cell dry weight. Despite the hydrophobic nature of $R$. erythropolis DCL14 ( Morrish et al., 2008), the quantification of biomass in presence of silicone oil was easily done considering the biomass contained in the aqueous phase, taking periodically aliquots of $10 \mathrm{~mL}$, and decanting the supernatant.

The removal efficiency of $\alpha$-pinene (RE, \%), the elimination capacity (EC, $\mathrm{g} \mathrm{m}^{-3} \mathrm{~h}^{-1}$ ) and the inlet loading rate (ILR, $\mathrm{g} \mathrm{m}^{-3} \mathrm{~h}^{-1}$ ) were estimated by using equations mentioned elsewhere (Kennes and Veiga, 2001, Kennes et al., 2009b and Rene et al., 2010).

\section{Results and discussion}

\subsection{Batch biodegradation experiments}

Before the continuous bioreactor studies, $\alpha$-pinene degradation experiments were carried out in closed flasks with or without silicone oil, in order to check $\alpha$-pinene degradation by the bacterial co-culture. The objective of this test was to check whether the microorganisms were able to mineralize $\alpha$-pinene. The results illustrated in Fig. 2a show the biodegradation profiles of $\alpha$-pinene using a single aqueous liquid phase, and Fig. $2 b$ shows the biodegradation of $\alpha$-pinene when adding $5 \%$ silicone oil to the aqueous liquid phase. From these profiles, it is evident that in presence of silicone oil, the removal of $\alpha$-pinene from the gas phase occurred almost instantaneously. When $4.29 \mathrm{mg} \alpha$-pinene was added to the test vial, complete mineralization occurred in about 
$60 \mathrm{~h}$ in presence of silicone oil, while only $3.18 \mathrm{mg} \alpha$-pinene was removed in as much as $432 \mathrm{~h}$, in the absence of silicone oil. Biomass growth and $\mathrm{CO}_{2}$ generation profiles were constantly monitored during the experiments, and by comparing Fig. 2a and b, it was observed that $\mathrm{CO}_{2}$ production rates and biomass growth increased with $\alpha$-pinene uptake. The experiments showed that in presence of silicone oil, biomass concentration increased by a factor of 29.8 within the first 3 days while, in the absence of silicone oil, biomass concentration only increased by a factor of 2.6 during the same period. A similar behaviour was observed with a Saccharomyces cerevisiae strain, where higher $\mathrm{CO}_{2}$ production rates together with higher biomass concentrations were observed in presence of a water-immiscible phase, usually attributed to an enhanced transfer of oxygen to the culture media ( Quijano et al., 2010). As evident from Fig. 2a, biomass growth reached its stationary phase in less than 3 days and subsequently the degradation rate of $\alpha$-pinene also decreased significantly. This can be attributed to substrate-induced toxicity to the biomass that inhibited the rate of substrate utilization. Oxygen was not the limiting factor, because experiments were performed in batch vials having a headspace of $\sim 100 \mathrm{~mL}$ (working volume $-10 \mathrm{~mL}$ ). Based on mass balance calculations (assuming air to contain $20.95 \%$ oxygen at STP), oxygen was present in excess to initiate the biodegradation of $4.5 \mathrm{mg} \alpha$-pinene. On the other hand, from Fig. $2 \mathrm{~b}$ it appears that, in presence of silicone oil, $4.29 \mathrm{mg} \alpha$-pinene generated about $12.5 \mathrm{mg}$ $\mathrm{CO}_{2}$. The theorical number of moles $\mathrm{CO}_{2}$ that could be formed, considering complete mineralization of $\alpha$-pinene and neglecting biomass growth, is $0.31 \mathrm{mmol}$, corresponding to $13.9 \mathrm{mg} \mathrm{CO}_{2}$, resulting in a value very close to the experimental one appearing in Fig. 2b, suggesting almost complete mineralization in batch experiments in presence of silicone oil. The discripency between the theoretical and experimental $\mathrm{CO}_{2}$ values can be attributed to the fact that the unaccounted $\mathrm{CO}_{2}$ could have been used for cellular growth and maintenance. Recent results from the literature show that no $\mathrm{CO}_{2}$ absorption takes place in batch vials saturated with $\mathrm{CO}_{2}$ and containing different proportions of oil/aqueous phase ( Rene et al., 2011b). 

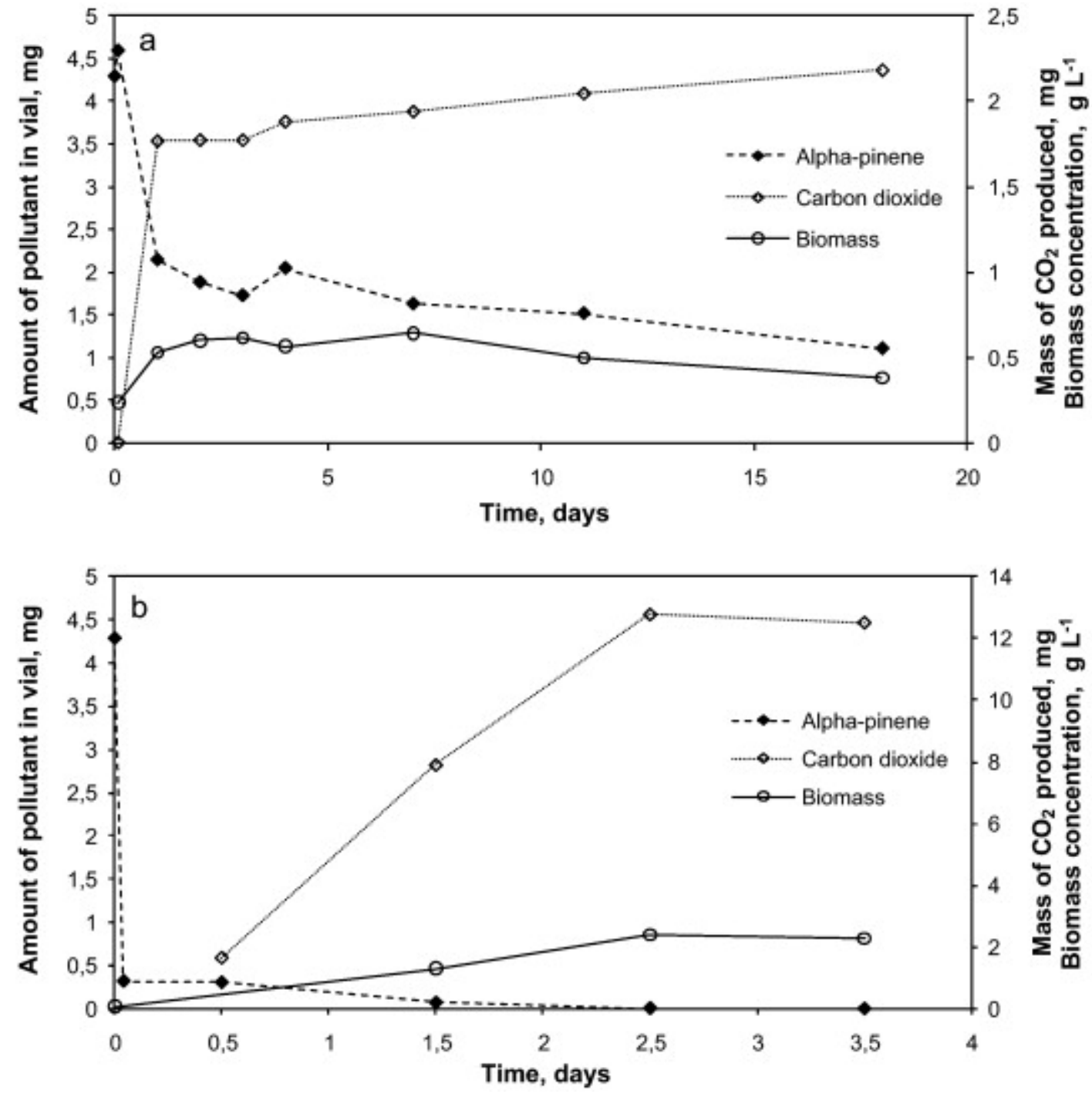

Fig. 2.

Biodegradation, biomass growth and $\mathrm{CO}_{2}$ generation profile in batch test vials inoculated with a mixed bacterial culture; (a) one-liquid-phase and (b) twoliquid-phase.

\subsection{Partition coefficients}

Partition coefficients experiments do not involve any complex reactions; hence the total solute mass present in the system is equal to the sum of solute mass in the evaluated phases. In our case, it can be expressed as follows (2),

$m_{\propto-\mathrm{p}}^{\mathrm{T}}=m_{\alpha-\mathrm{p}}^{\mathrm{L}}+m_{\propto-\mathrm{p}}^{\mathrm{G}}$

where, $m^{\mathrm{T}}$ represents the total mass of $\alpha$-pinene in the system while $m^{\mathrm{L}}$ and $m^{\mathrm{G}}$ represent the mass of $\alpha$-pinene in the liquid phase (water or silicone oil) or in the gas phase, respectively. The total mass of $\alpha$-pinene present in the system varied from 0.4 to $4 \mathrm{mg}$, corresponding to an $\alpha$-pinene volume injection from 0.5 to $5 \mu \mathrm{L}$. Thus, during these experiments, the concentrations of $\alpha$-pinene in the oil and water phase varied between 37 and 94 and 4 and $70 \mathrm{~g} \mathrm{~m}^{-3}$, respectively. The $\alpha$-pinene water/air and oil/air partition coefficients appearing in Table 1 confirm that $\alpha$-pinene is hardly soluble in water while 
its solubility is higher in oil. Recent studies show experimental $\alpha$-pinene partition coefficients for different organic solvents, ranging from 0.001370 to 0.000052 (expressed as $P\left(C_{\mathrm{g}} / C_{\mathrm{L}}\right)$ ), which highlights the great affinity of the organic solvents for $\alpha$-pinene ( Muñoz et al., 2008). Other studies were carried out using olive oil, showing also a higher partition coefficient compared with the corresponding values in water ( Falk et al., 1990). As published by Bir (2000), in presence of silicone oil, the partition coefficient exhibits a nonlinear decay as the temperature increases. Moreover, although $\alpha$-pinene is highly soluble in silicone oil, a certain contact time between oil and $\alpha$ pinene would be required to effectively trap and remove the species from a given effluent. The results show that silicone oil is a reasonably good medium for trapping $\alpha$ pinene.

Table 1. $\alpha$-Pinene partition coefficients for water/air or oil/air.

\begin{tabular}{||l|l|l|l|l||}
\hline & \multicolumn{3}{|l||}{ Temperature, ${ }^{\circ} \mathbf{C}$} \\
& 30 (this study) & 30 (Muñoz et al., 2008) & 37 (Falk et al., 1990) & 50 (Bir, 2000) \\
\hline \hline$\left.P_{(\text {water }, \alpha-p)}\right)$ & 2.31 & N/A & 0.12 & N/A \\
\hline$P_{(\text {oil }, \alpha-p)}$ & 4968 & 5464 & 2900 & 825 \\
\hline
\end{tabular}

N/A = not available.

\subsection{Influence of silicone oil concentration on the uptake of biomass from the aqueous phase}

The uptake of biomass from the aqueous phase to the water/oil emulsion was evaluated. To this end, different percentages of silicone oil, between 0 and $50 \%$, were tested. A $24 \mathrm{~h}$ stabilization period was needed for the water/silicone oil emulsion to stop absorbing more biomass. When the oil concentration was $10 \%$, it was shown that the system was well stabilized after the optical density had decreased by about $44 \%$ (Fig. $3 a$ ). As expected, when the oil concentration was increased to $20 \%$, more biomass was absorbed, resulting in a further decrease in the optical density of the aqueous phase. Nevertheless, when the oil concentration was increased from $20 \%$ to $50 \%$ no significant differences were observed anymore in the uptake of biomass (Fig. 3b). In our case, the absorption of biomass into the water/oil emulsion in the bioreactor was evaluated by adjusting the curve to a polymeric function, with a value of the absorption of biomass of about $11 \%$ and 26\%, using 2 and 5\% silicone oil, respectively. During the batch experiments, an inverse emulsion of water droplets containing the cells was observed. Even though the Rhodococcus strain shows strong adherence to oil because of its hydrophobicity, migration of some of the cells into the oil phase makes this emulsion less stable and reduces the volume of the emulsion ( Déziel et al., 1999). Previously, other authors had evaluated the absorption of biomass into the oil phase obtaining a value of about $30 \%$ absorption, using a medium composed of $10 \% \mathrm{v} / \mathrm{v}$ silicone oil ( Aldric et al., 2010). The amount biomass that can be absorbed into the organic phase will presumably depend on the characteristics of the biomass and the physical properties of the oil, among others. 

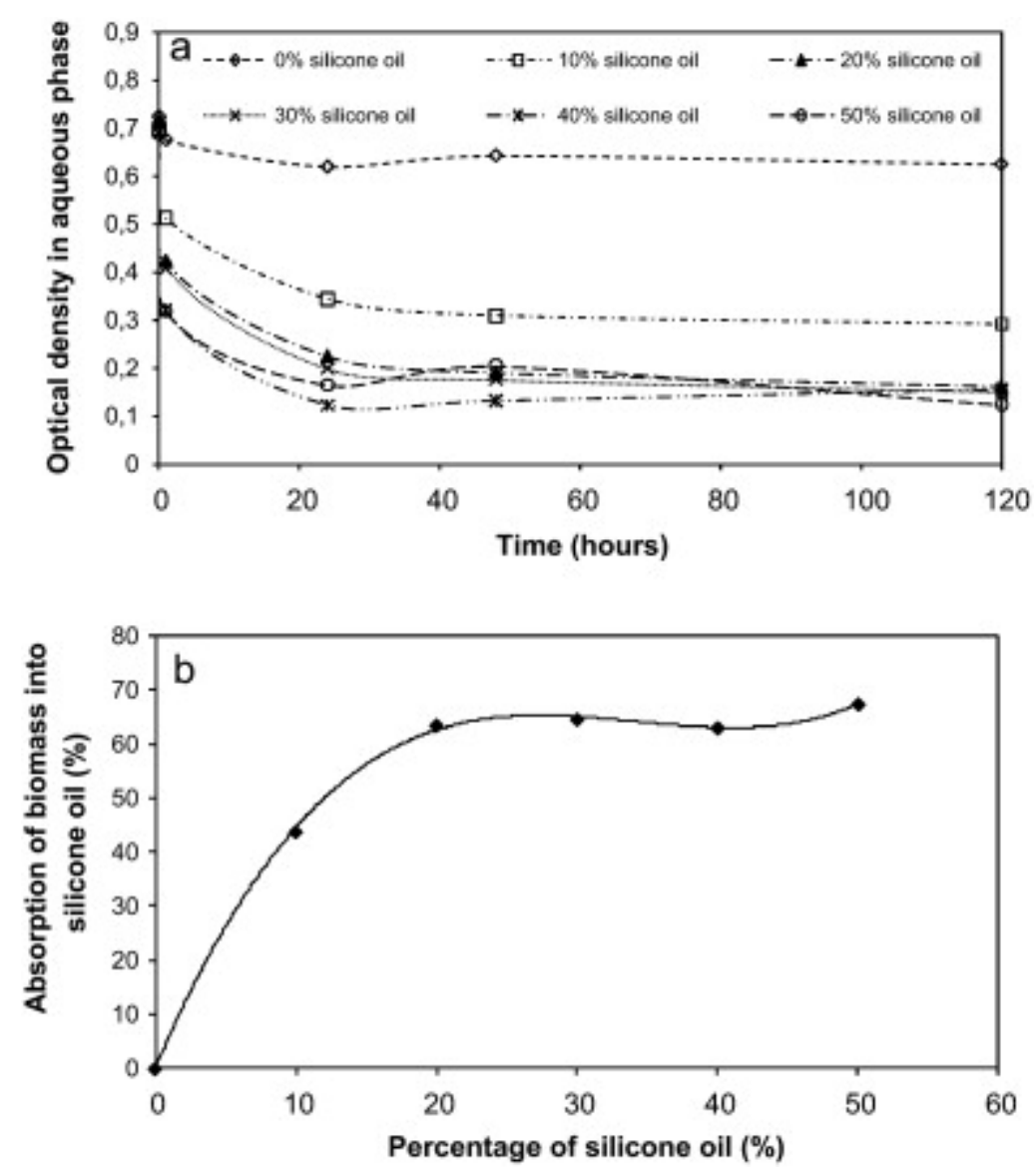

Fig. 3.

(a) Variation of the optical density in aqueous phase over time for different percentages of silicone oil and (b) effect of silicone concentration on the absorption of biomass.

\subsection{Performance of the one-liquid-phase bioreactor}

The main objective of this experiment was to study the removal of $\alpha$-pinene in a CSTB in two experimental steps: firstly, using a single-liquid aqueous phase and secondly, using a mixture of an aqueous-organic liquid phase.

In the first experiment, done without any addition of silicone oil, $\alpha$-pinene removal was investigated under different conditions corresponding to decreasing RTs of $120 \mathrm{~s}, 60 \mathrm{~s}$, $36 \mathrm{~s}$ and $26 \mathrm{~s}$. The CSTB was initially acclimated to $\alpha$-pinene by feeding low concentrations at low gas flow rates $\left(0.042 \mathrm{~m}^{3} \mathrm{~h}^{-1}\right)$. At a RT of $120 \mathrm{~s}, 80 \%$ RE could be maintained at an inlet concentration of $0.3 \mathrm{~g} \mathrm{~m}^{-3}$ corresponding to a load of $8 \mathrm{~g} \mathrm{~m}^{-3} \mathrm{~h}^{-1}$ during start-up. The RE gradually decreased when further increasing the load and reached a maximum EC of $320 \mathrm{~g} \mathrm{~m}^{-3} \mathrm{~h}^{-1}$ at a load of $489 \mathrm{~g} \mathrm{~m}^{-3} \mathrm{~h}^{-1}$ (Fig. 4), resulting in a RE of $65 \%$. In the next phase, the flow rate was increased to $0.084 \mathrm{~m}^{3} \mathrm{~h}^{-1}$ corresponding to a RT of $60 \mathrm{~s}$, for inlet loads varying between 7 and $700 \mathrm{~g} \mathrm{~m}^{-3} \mathrm{~h}^{-1}$. The removal efficiencies were high at a low inlet loading rate and decreased gradually when increasing the loading rate. When the concentration was increased, the RE steadily dropped to reach a minimum value of about $60 \%$. Near complete $\alpha$-pinene removal could only be maintained at relatively low loads, below $100 \mathrm{~g} \mathrm{~m}^{-3} \mathrm{~h}^{-1}$ (Fig. 4). A maximum EC of $322 \mathrm{~g} \mathrm{~m}^{-3} \mathrm{~h}^{-1}$ was then achieved with $60 \% \mathrm{RE}$. 


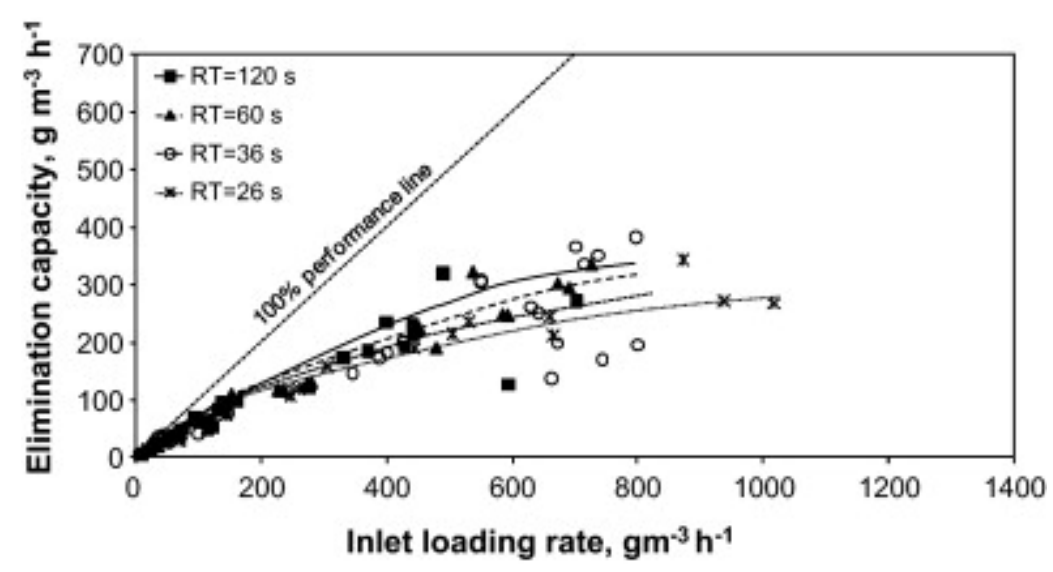

Fig. 4.

Effect of inlet loading rate on the elimination capacity of the one-liquid-phase continuous stirred tank bioreactor.

The next two phases of operation were aimed at investigating the CSTB performance at lower RTs of 36 and $26 \mathrm{~s}$. At a RT of $36 \mathrm{~s}$, the gas flow rate was increased up to $0.15 \mathrm{~m}^{3} \mathrm{~h}^{-1}$, with inlet loads varying between 6 and $800 \mathrm{~g} \mathrm{~m}^{-3} \mathrm{~h}^{-1}$. The CSTB was able to maintain $\mathrm{RE}>85 \%$, up to inlet concentrations around $0.45 \mathrm{~g} \mathrm{~m}^{-3}$ corresponding to a load of $44 \mathrm{~g} \mathrm{~m}^{-3} \mathrm{~h}^{-1}$. A maximum EC of $382 \mathrm{~g} \mathrm{~m}^{-3} \mathrm{~h}^{-1}$ was achieved with $48 \%$ removal in this phase.

Finally, in the next phase, at a RT of $26 \mathrm{~s}$, the gas flow rate was increased up to $0.21 \mathrm{~m}^{3} \mathrm{~h}^{-1}$ and the inlet loads varied between 5 and $1000 \mathrm{~g} \mathrm{~m}^{-3} \mathrm{~h}^{-1}$. The CSTB maintained $\mathrm{RE}>80 \%$ up to a concentration of $0.13 \mathrm{~g} \mathrm{~m}^{-3}$ corresponding to a load of $19 \mathrm{~g} \mathrm{~m}^{-3} \mathrm{~h}^{-1}$. A maximum EC of $343 \mathrm{~g} \mathrm{~m}^{-3} \mathrm{~h}^{-1}$ was achieved with $39 \%$ RE.

Some relationship was found between the RT and the critical load of the CSTB when the RT was reduced from $120 \mathrm{~s}$ to $26 \mathrm{~s}$ in the absence of oil, although the behaviour was not really significantly different at all four RT. In other types of bioreactors such as fungal biofilters, it was observed that the maximum EC of $\alpha$-pinene decreased when lowering the RT, although the influence was much more significant in packed-bed bioreactors than in the present study with the suspended-growth reactor (Jin et al., 2006 and Jin et al., 2007). Also, the same behaviour was found for a fungal CSTB inoculated with Sporothrix variecibatus, in which styrene biodegradation was studied ( Rene et al., 2011b).

Although biodegradation studies with fungi often reach contaminant removal rates equal or greater than those observed in bacterial systems, this work is a good example that bacteria may sometimes also be particularly suitable for biodegradation applications, also for hydrophobic pollutants with low degradation such as $\alpha$-pinene. Jin et al. (2006) reported an EC of $143 \mathrm{~g} \alpha$-pinene $\mathrm{m}^{-3} \mathrm{~h}^{-1}$ in a biofilter inoculated with the fungus Ophiostoma stenoceras. In that study, enriching the air with oxygen (45\%) improved the removal of $\alpha$-pinene, and a maximum EC of $187 \mathrm{~g} \mathrm{~m}^{-3} \mathrm{~h}^{-1}$ was then reported. Under mesophilic conditions, the maximum EC reported more recently for $\alpha$ pinene in a biotrickling filter inoculated with the fungus Ophiostoma sp. was $232 \mathrm{~g} \mathrm{~m}^{-3} \mathrm{~h}^{-1}$ at an inlet load of $464 \mathrm{~g} \mathrm{~m}^{-3} \mathrm{~h}^{-1}$ ( Montes et al., 2010). Although these values are 5-60 times higher than the values obtained in bacteria-dominant systems ( Kleinheinz et al., 1999, Langolf and Kleinheinz, 2006 and van Groenestijn and Liu, 
2002), they are lower than the maximum EC reached in this study with a one-liquid phase CSTB (382 $\mathrm{g} \mathrm{m}^{-3} \mathrm{~h}^{-1}$ ). Several studies have also reported the removal of $\alpha$-pinene under thermophilic conditions $\left(40-55^{\circ} \mathrm{C}\right)$. The maximum EC reached for $\alpha$-pinene in a biotrickling filter, at $50{ }^{\circ} \mathrm{C}$, was $332 \mathrm{~g} \mathrm{~m}^{-3} \mathrm{~h}^{-1}$, although some studies have shown the optimal treatment for $\alpha$-pinene occurs at $55^{\circ} \mathrm{C}$ ( Kong et al., 2001 and Montes et al., 2010). At $40^{\circ} \mathrm{C}$ (bed temperature) and at an RT of $20 \mathrm{~s}$, a biofilter packed with wood chips and spent mushroom compost treated up to 40-50 g $\alpha$-pinene $\mathrm{m}^{-3} \mathrm{~h}^{-1}$ with REs $>90 \%$ ( Mohseni and Allen, 2000). Those results show that the degree of $\alpha$-pinene removal achieved in different waste-gas treatment systems (a biofilter, a biotrickling filter or a CSTB) depend on the operating temperature, the type of inoculum, nutrient medium composition and the type of packing material, among others.

\subsection{Performance of the two-liquid-phase bioreactor}

As can be observed from the literature, the addition of a second, organic-liquid phase, as silicone oil, usually increases the RE and maximum EC of hydrophobic compounds. In this part of the research the effect of adding an organic phase such as silicone oil was studied, at a volume ratio of either $2 \%$ or $5 \%$ of the liquid phase. As with the oneliquid-phase system, the bioreactor performance was investigated in different steps that correspond to decreasing RTs of $120 \mathrm{~s}, 60 \mathrm{~s}, 36 \mathrm{~s}$ and $26 \mathrm{~s}$. The inlet $\alpha$-pinene concentration was gradually increased in order to evaluate the reactor's performance. Although the experimental data fluctuated somewhat, as a general rule it can be concluded that higher removals were obtained at the highest RT (i.e., lowest flow rates) both with $2 \%$ (Fig. 5) and with 5\% silicone oil (Fig. 6). With an increase in the gas-RT, the removal of $\alpha$-pinene by the microorganisms also increased, because the contact time between cells in suspension and $\alpha$-pinene also increased. This implies that the microorganisms have enough time to consume the substrate and as a result an increase in the removal of $\alpha$-pinene was observed.

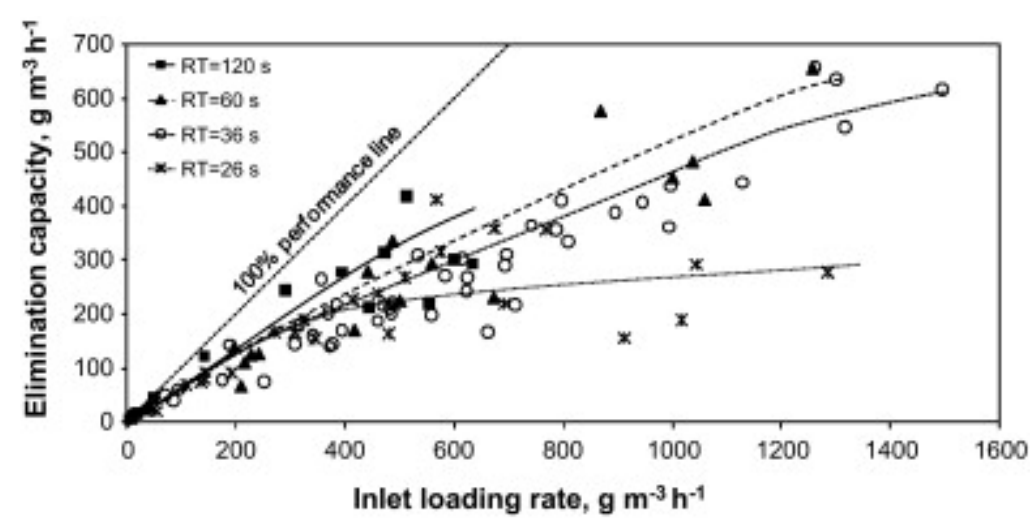

Fig. 5.

Effect of the addition of $2 \%$ silicone oil on the elimination capacity of the continuous stirred tank bioreactor. 


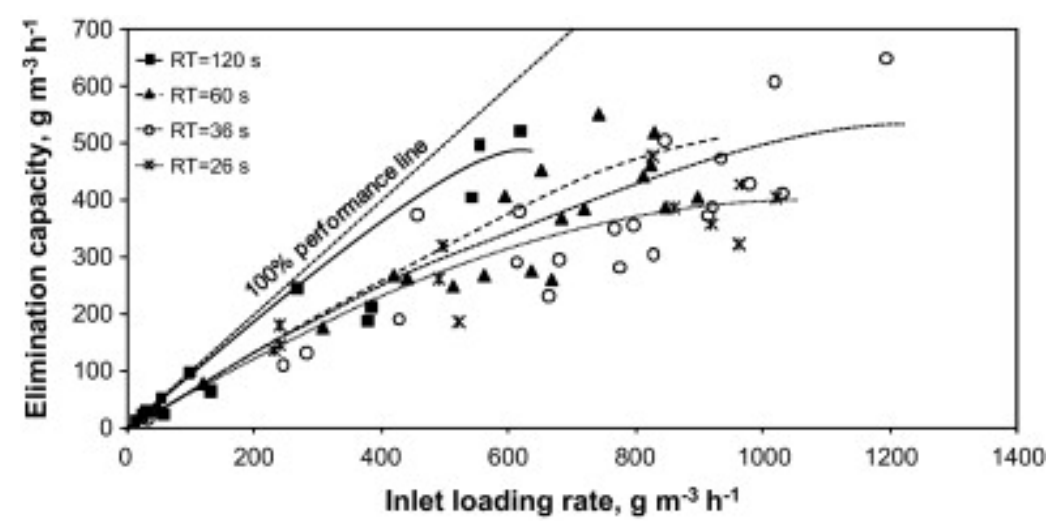

Fig. 6.

Effect of the addition of $5 \%$ silicone oil on the elimination capacity of the continuous stirred tank bioreactor.

The data also show that the presence of a second, organic phase improved the overall performance. Although somewhat better results were generally reached with 5\% silicone oil, a similar improvement was already observed with the addition of $2 \%$ organic phase as well. The results were not statistically different enough to allow to distinguish between 2 and 5\% oil. The maximum EC in the system with silicone oil was around $650 \mathrm{~g} \mathrm{~m}^{-3} \mathrm{~h}^{-1}$, with a RE of $55 \%$, which is 1.7 times higher than in the oneliquid phase bioreactor. This would allow reducing the reactor volume and investment cost in the presence of silicone oil in full-scale applications. It is assumed that silicone oil enhances the oxygen mass transfer by acting as a surface-active agent. It lowers the surface tension of water and increases the gaseous specific interfacial area. Several studies have found that the addition of silicone oil hinders oxygen mass transfer compared to a water system. Such decrease in the oxygen mass transfer, which implies longer aeration times to transfer oxygen, could be a limiting step in biotechnological processes strongly dependent on oxygen concentration. However, as silicone oil presents a large affinity for oxygen (seven times higher than for water), enabling larger amounts of oxygen to be transferred from the gas phase, the addition of more than 5\% silicone oil should be beneficial to increase the oxygen transfer rate. Moreover, it was found for several compounds, such as styrene and $n$-decane, that their volumetric mass transfer coefficient from the gas phase to a water-silicone oil emulsion is independent of the emulsion's composition ( Dumont et al., 2006 and Peeva et al., 2001). As shown in the results of this work and from the literature information, a small fraction of silicone oil $(5 \% v / v)$ may be enough to provide an enhancement of $\alpha$-pinene and oxygen absorption in bioreactor configurations such as CSTBs and BTFs. Since the amount organic phase to be added will affect the overall treatment costs, it is of prime importance to optimize that parameter. There is no clear rule that allows to decide on the amount of non-aqueous phase that should be added to a CSTB, which basically depends on the solvent properties, VOC diffusivity and the type of microorganisms used ( Muñoz et al., 2007 and Rene et al., 2011b). In the literature, organic to aqueous phase ratios between 5 and $50 \%$ have been reported, no data are available on lower ratios, except for this study. In Table 2 recent data are summarized for different gas-phase pollutants tested in one- and two-liquid phase CSTBs and the corresponding maximum loads and ECs are reported. From the data of Table 2, it appears that it has become unusual to work with high concentrations of organic phase for environmental applications, according to recent literature. It is shown that the addition of an organic phase increases significantly biodegradation performance in a stirred tank, making two- 
phase partitioning bioreactors a promising alternative to improve VOCs removal in bioreactors. Some other studies have described the use of silicone oil for the treatment of $\alpha$-pinene contaminated air. Hejazi et al. (2010) compared the removal of $\alpha$-pinene in a biofilter packed with perlite partially coated with silicone oil, with a biofilter packed with perlite. The results showed a maximum EC of $40 \mathrm{~g} \mathrm{~m}^{-3} \mathrm{~h}^{-1}$, and in that case this value was only slightly higher than in the biofilter operated without oil. Furthermore, the authors observed that, during later runs, similar ECs were achieved for both the systems $\left(\sim 45 \mathrm{~g} \mathrm{~m}^{-3} \mathrm{~h}^{-1}\right)$. This was attributed to an increase in the number of microorganisms in the system without oil. Similar studies were performed in an agitated bioreactor using Pseudomonas fluorescens as the inoculum, and $10 \%$ of HMN (2,2,4,4,6,8,8-heptamethylnonane) and FC40 (electronic fluid) as the second liquid phase ( Muñoz et al., 2008). A significant enhancement (7-12-fold increase) in the transfer of $\alpha$-pinene from the gas-phase to the liquid phase was reported in the bioreactor due to the presence of HMN and FC40, when compared to the bioreactor operated without second liquid phase. Besides, the authors reported that the presence of the second liquid phase also increased the EC values 1.5-fold when compared to the operation with a single liquid phase. In a previous work, the addition of silicone oil to a biotrickling filter inoculated with an Ophiostoma sp., improved the removal of $\alpha$-pinene and EC values as high as $3849 \mathrm{~g} \mathrm{~m}^{-3} \mathrm{~h}^{-1}$ with $98 \% \mathrm{RE}$ were reported ( Montes et al., 2010). Some differences exist in the results reported on the treatment of $\alpha$-pinene in different biological systems and different factors should be considered in order to compare these results, such as the characteristics of the packing material, the inoculum used or the nature and characteristics of the organic phase. 
Table 2.

Performance reported in recent publications for the removal of several VOCpollutants from air, in stirred tank bioreactors.

\begin{tabular}{|c|c|c|c|c|c|}
\hline Pollutant & Reactor & Organic liquid phase & Load $^{\mathrm{a}}$ & $\mathbf{E C}^{\mathbf{a}}$ & References \\
\hline \multirow{2}{*}{ Hexane } & One-liquid-phase & & 180 & 50 & \multirow{2}{*}{ Arriaga et al. (2006) } \\
\hline & Two-liquid-phase & Silicone oil (10\%) & 180 & 120 & \\
\hline \multirow{2}{*}{ Hexane } & One-liquid-phase & & 180 & 45 & \multirow{2}{*}{ Muñoz et al. (2006) } \\
\hline & Two-liquid-phase & Silicone oil (10\%) & 180 & 160 & \\
\hline \multirow{2}{*}{ Hexane } & One-liquid-phase & & 65.6 & 5.9 & \multirow{2}{*}{ Hernández et al. (2010) } \\
\hline & Two-liquid-phase & Silicone oil (20\%) & 65.6 & 10.6 & \\
\hline \multirow{3}{*}{$\alpha$-Pinene } & One-liquid-phase & & 24 & 4 & \multirow{3}{*}{ Muñoz et al. (2008) } \\
\hline & Two-liquid-phase & FC $40(10 \%)$ & 24 & 10 & \\
\hline & Two-liquid-phase & HMN (10\%) & 24 & 19.2 & \\
\hline \multirow{2}{*}{ Dichloromethane } & One-liquid-phase & & 125 & 117 & \multirow{2}{*}{ Bailón et al. (2009) } \\
\hline & Two-liquid-phase & Silicone oil (10\%) & 500 & 350 & \\
\hline \multirow{3}{*}{ Methane } & One-liquid-phase & & 209 & 75 & \multirow{2}{*}{ Rocha-Rios et al. (2009) } \\
\hline & \begin{tabular}{|l|} 
Two-liquid-phase \\
\end{tabular} & Silicone oil (10\%) & 187 & 106 & \\
\hline & Two-liquid-phase & Silicone oil (10\%) & 65 & 45.5 & Rocha-Rios et al. (2010) \\
\hline \multirow{2}{*}{ Styrene } & One-liquid-phase & & 207 & 137 & \multirow{2}{*}{ Rene et al. (2011b) } \\
\hline & Two-liquid-phase & Silicone oil (10\%) & 548 & 426 & \\
\hline
\end{tabular}

an $\mathrm{g} \mathrm{m}^{-3} \mathrm{~h}^{-1}$.

\subsection{Biomass concentration}

As indicated before, the bioreactor was autoclaved and new fresh medium and microorganisms were added after each experiment. The biomass concentration was measured as dry biomass weight per $\mathrm{L}$ aqueous medium. In all cases, the biomass concentration was initially low during start-up $\left(0.5 \mathrm{~g} \mathrm{~L}^{-1}\right)$, increasing slowly until reaching a constant value. This is illustrated for the reactor operated at a RT of $120 \mathrm{~s}$ where the biomass concentration gradually increased to about $6 \mathrm{~g} \mathrm{~L}^{-1}$; after which it remained basically unchanged (Fig. 7). According to the observations and suggestions given in the literature, the experiments were allowed to naturally achieve a stable biomass concentration without addition or removal of biomass from the system. Once the biomass concentration reaches steady-state, experiments can be conduced (Nielsen et al., 2005). Thus, steady-state experiments were conduced once the biomass concentration had reached near steady-state values, i.e., after 27 days of operation in this case (Fig. 7). The biomass concentrations in the CSTB stabilized in all the experiments at values between $\sim 5$ and $6.3 \mathrm{~g} \mathrm{~L}^{-1}$, after an acclimation period of 27 days. Similarly, Aldric and Thonart (2008) reported that 19 days were needed with $R$. erythropolis T901.2 to reach a steady-state biomass concentration in a bioreactor treating isopropylbenzene. 


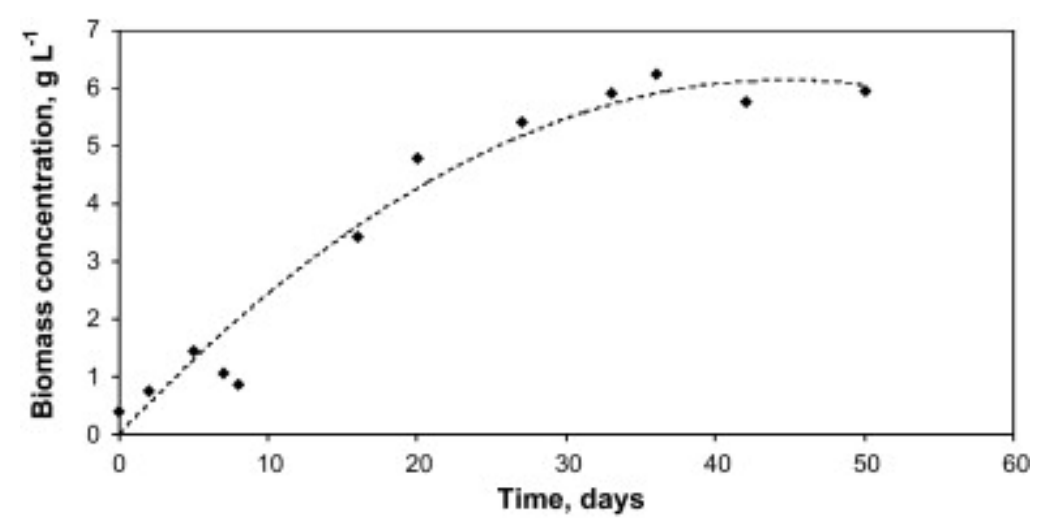

Fig. 7.

Example of biomass concentrations in the aqueous phase during the experiment with $5 \%$ silicone oil at a RT of $120 \mathrm{~s}$.

\subsection{Mass balance calculations}

During the experiments, carbon dioxide concentrations were also monitored by calculating the difference between the reactor's inlet and outlet $\mathrm{CO}_{2}$ concentrations. The bacterial co-culture was grown in an aqueous nutritive solution at $\mathrm{pH} 7$ in presence of $\alpha$ pinene, demonstrating its ability to use that compound as carbon and energy source. Carbon dioxide was identified as major end-product, part of the substrate being also converted into biomass. The yield coefficient of biomass on $\alpha$-pinene was determined from shake flask experiments (working volume - $10 \mathrm{~mL}$ ), reaching $1.19 \mathrm{mg}$ dry biomass produced/mg $\alpha$-pinene consumed (Fig. 2a). A typical cellular composition can be represented by the formula $\mathrm{C}_{4} \mathrm{H}_{8} \mathrm{NO}_{2}$ (Kennes and Veiga, 2001). Taking into account the fact that $\left(\mathrm{NH}_{4}\right)_{2} \mathrm{SO}_{4}$ was the nitrogen source and considering the yield coefficient, one can deduce the following stoichiometric equation:

$$
\mathrm{C}_{10} \mathrm{H}_{16}+9.75 \mathrm{O}_{2}+0.5\left(\mathrm{NH}_{4}\right)_{2} \mathrm{SO}_{4} \rightarrow \mathrm{C}_{4} \mathrm{H}_{8} \mathrm{NO}_{2}+5.5 \mathrm{H}_{2} \mathrm{O}+6 \mathrm{CO}_{2}+0.5 \mathrm{H}_{2} \mathrm{SO}_{4}
$$

It is well known that heterotrophic bacteria are obligate osmotrophs, requiring dissolved nutrients for growth. Therefore, the abundance of various cellular components can have a significant effect of the total cell stoichiometry. Generally, bacteria need to adjust their growth rate to respond to environmental conditions, such as nutrient limitation. This problem was avoided in our system by the addition of sterilized fresh medium, periodically, to compensate for water losses by evaporation and to solve, at the same time, possible nutrient limitation problems (Gruber, 2007).

For complete biodegradation of $\alpha$-pinene to $\mathrm{CO}_{2}$ and water, and when biomass growth is taken into account, with ammonium sulphate as nitrogen source, the mass-ratio of $\mathrm{CO}_{2}$ produced per gram $\alpha$-pinene degraded should be 1.9. The theorical number of moles of $\mathrm{CO}_{2}$ that should be produced per mole $\alpha$-pinene eliminated is 6 and should, in any case, not exceed 10, whenever neglecting biomass growth, since $1 \mathrm{~mol}$ of $\alpha$-pinene $\left(\mathrm{C}_{10} \mathrm{H}_{16}\right)$ would then yield $10 \mathrm{~mol}$ of $\mathrm{CO}_{2}$, as described previously (Jin et al., 2006). The correlation between the $\mathrm{CO}_{2}$ production rate and the EC, without and with $5 \%$ oil, is presented in Fig. 8. According to the stoichiometric reactions mentioned previously, the ratio of $\mathrm{CO}_{2}$ produced to the amount of $\alpha$-pinene consumed should be 1.9. From the regression equations shown in Fig. 8, it is observed that the ratio of $\mathrm{CO}_{2}$ produced to the 
amount of $\alpha$-pinene consumed was close to 1.06 and 0.504 respectively, which are lower values than the theoretical ones. However, substrate used for biomass growth should also be considered. In this study, discrepancies between theoretical and observed $\mathrm{CO}_{2}$ profiles were also found. A similar behaviour was observed in the three different situations studied. As sometimes already observed and reported by others, besides substrate biodegradation, total $\mathrm{CO}_{2}$ production can also result from endogenous respiration of the biomass and other phenomena (Diks et al., 1994, Fang and Govind, 2006 and Jin et al., 2006). In any case, those high $\mathrm{CO}_{2}$ concentrations confirm that the pollutant was presumably almost completely biodegraded to end products.

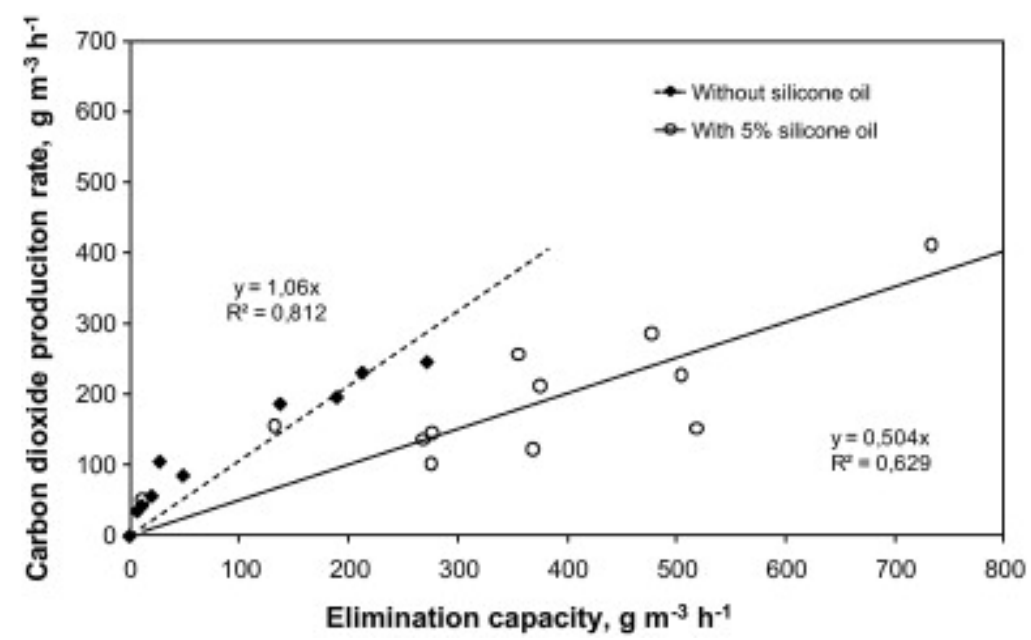

Fig. 8.

Relationship between carbon dioxide production rate and elimination capacity of the continuous stirred tank bioreactor with and without 5\% silicone oil.

\subsection{Shock-loads}

Gas-phase bioreactors can tolerate moderate shock-loads well, but their ability to handle high shock-loads needs to be evaluated better because the microorganisms may find it difficult to tolerate such situations (Bailón et al., 2009, Nielsen et al., 2005 and Rene et al., 2011b). As industrial effluents may show variable loading patterns, it is important to test the bioreactors stability under shock-load conditions, in terms of both medium and high over-loads, and evaluate the shock handling capacity of the microorganisms. Shock loading studies were carried out at loading rates varying from $80 \pm 20$ to $1000 \pm 200 \mathrm{~g} \mathrm{~m}^{-3} \mathrm{~h}^{-1}$ in absence of an organic phase, in presence of $2 \%$ silicone oil, and in presence of $5 \%$ silicone oil. In all cases, the load was increased from low to high values and overload conditions were then maintained for $8 \mathrm{~h}$, at a RT of $36 \mathrm{~s}$. These high loading rates were achieved by increasing the low flow rate of the secondary stream of air passing through the vial containing pure $\alpha$-pinene and by adjusting the, higher, primary flow rate of the humidified stream of air, in order to maintain a constant RT.

For the CSTB without the addition of an organic phase (Fig. 9a), during the first $2 \mathrm{~h}$, a constant RE was noticed. However, when the shock-load of $1200 \mathrm{~g} \mathrm{~m}^{-3} \mathrm{~h}^{-1}$ was suddenly applied, the total $\alpha$-pinene removal decreased from about 40 to $20 \%$ during the first hour, after which the RE remained almost constant. Once the original, low, load 
was restored, the system gradually recovered, although temporarily negative values $(\mathrm{RE}<0 \%)$ were reached as a result of the hydrodynamics of the system.
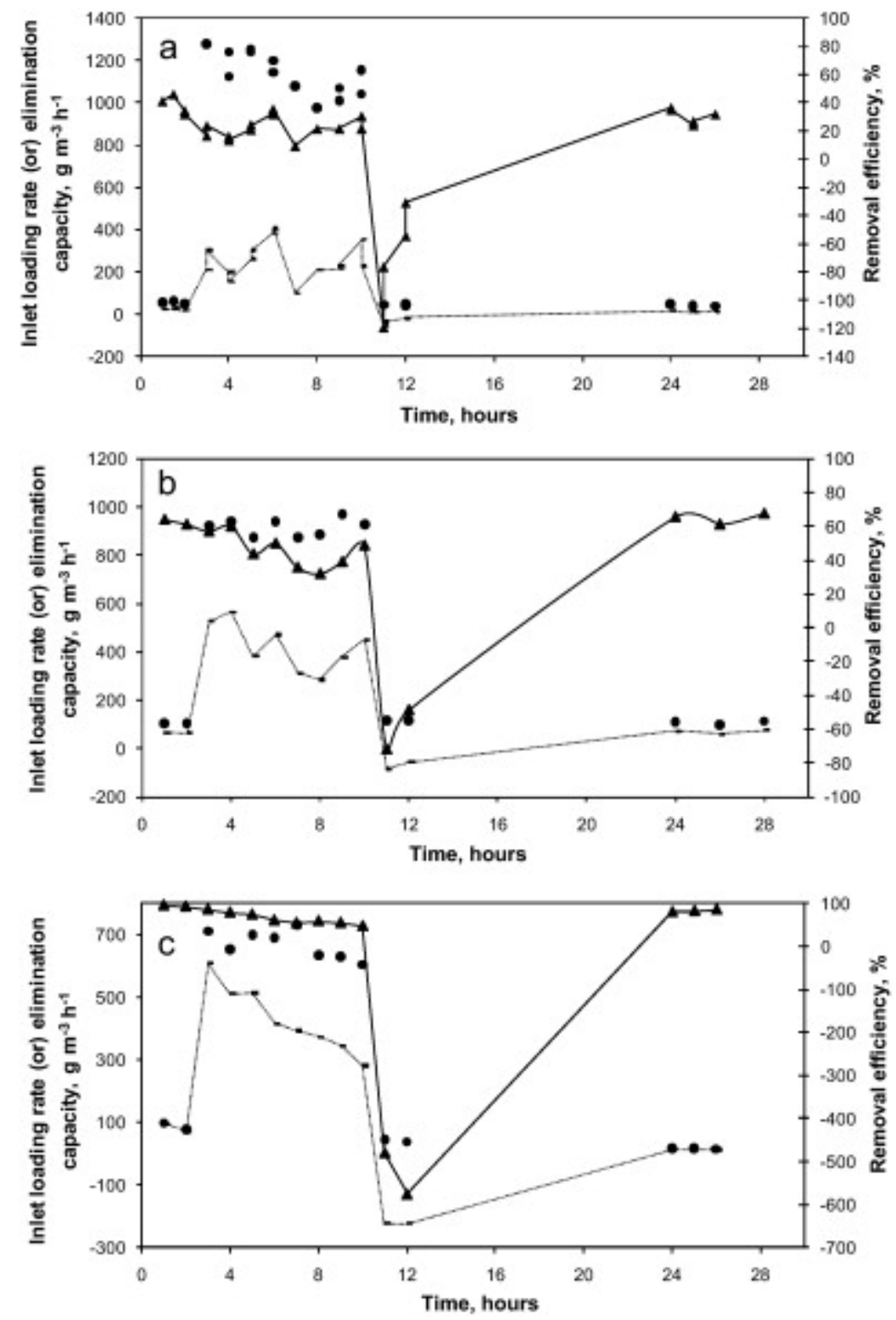

Fig. 9.

Inlet load, outlet load and RE vs time during the shock-load experiment without oil (a), with $2 \%$ oil (b), and with $5 \%$ oil (c). Circles $(\bullet)$ represent inlet loading rate, lines $(-)$ represent elimination capacity, and triangles $(\boldsymbol{\wedge})$ represent the removal efficiency of $\alpha$-pinene in the system.

Similar studies were carried out using $2 \%$ silicone oil as an organic liquid phase (Fig. 9b). During the first $2 \mathrm{~h}$ a constant loading rate of $100 \mathrm{~g} \mathrm{~m}^{-3} \mathrm{~h}^{-1}$ was applied, with a RE of $60 \%$ just before the shock-load. When the shock-load was applied, reaching an inlet loading rate close to $1000 \mathrm{~g} \mathrm{~m}^{-3} \mathrm{~h}^{-1}$, the RE remained basically constant for the first $2 \mathrm{~h}$. After that it decreased down to $40 \pm 8 \%$ during the next $6 \mathrm{~h}$. Again, once the original load was restored, a negative RE was observed for a short period, very similar as in the previous experiment without oil. 
In the case of $5 \%$ silicone oil (Fig. 9c), a constant loading rate of $100 \mathrm{~g} \mathrm{~m}^{-3} \mathrm{~h}^{-1}$ was maintained for $2 \mathrm{~h}$, reaching a $\mathrm{RE}>90 \%$. When the shock-load was applied, reaching an ILR rate of $750 \mathrm{~g} \mathrm{~m}^{-3} \mathrm{~h}^{-1}$, the RE decreased to $46 \% 8 \mathrm{~h}$ later and then again, when the shock-load was stopped, negative RE values were reached. The fact that quite lower, negative, RE were reached for a short time in presence of $5 \%$ silicone oil than in its absence can be explained by the absorption of $\alpha$-pinene in the oil phase and its subsequent slow release to the aqueous and gas phases just after the shock-load, resulting in higher pollutant concentrations at the outlet than at the inlet of the system for a short period.

The performance and stability of the reactors at the end of the $8 \mathrm{~h}$ shock-load were best with $5 \%$ silicone oil, since the RE only dropped by about $50 \%$. In case of only $2 \%$ silicone oil, the RE dropped to about $40 \%$ after $8 \mathrm{~h}$, while it dropped to about $20 \%$ in the absence of silicone oil. The recovery of the CSTB after the shock-load was also better with oil than without it. Indeed, when restoring the original, low, load, the RE immediately reached almost $100 \%$ in presence of $5 \%$ oil, while this parameter reached about $60-70 \%$ and $30-40 \%$ respectively, with $2 \%$ oil and without any oil. When the shock-load is applied, the excess $\alpha$-pinene concentration is absorbed into the organic phase because of the higher affinity of $\alpha$-pinene for silicone oil compared to water. However, when the load is reduced during the post-shock phase, some $\alpha$-pinene is still captured within the organic phase, and the non-treated and non-captured $\alpha$-pinene is vented through the outlet. Hence, during the initial few hours after the shock-load phase, the inlet concentration of $\alpha$-pinene is less than the outlet concentration, thus giving rise to negative REs.

Biomass could also absorb pollutants. In order to determine the exact amount of $\alpha$ pinene absorbed by the suspended biomass in the CSTB, further studies would be needed in batch and continuous systems wherein sterilized (killed) cells should be used instead of live biomass.

\section{Conclusions}

This paper presents the performance of $\alpha$-pinene removal in a suspended-growth bioreactor, inoculated with a mixed bacterial culture, operating under different conditions. The results from this experimental study show that the two-liquid-phase CSTB performs always better than the one-liquid-phase reactor, in terms of maximal performance (highest maximum EC and highest RE). A small fraction of silicone oil, either 2 or $5 \%$, is enough to provide an enhancement of $\alpha$-pinene biodegradation, maintaining costs low due to the addition of only low amounts of organic phase. In addition, the suspended-growth bioreactor provides a high degree of $\alpha$-pinene mineralization at low inlet loading rates, converting $\alpha$-pinene basically completely to carbon dioxide and water. Finally, the response of the CSTB to shock-loads was better in presence of an organic phase, both in terms of the reactor's performance during overload conditions and in terms of the speed of the reactor's recovery after the shockloads. The system can better withstand shock-loads because of the buffering effect of the organic phase. 


\section{Acknowledgements}

The present research was financed through a project of the Spanish Ministry of Science and Innovation (CTM2007-62700/TECNO) and through European FEDER funds. The doctoral research of MMC is financed by the University of La Coruña (Spain). We thank M.E. López and E.R. Rene for their collaboration. The organism, R. erythropolis DCL14, was donated by the Center for Biological and Chemical Engineering of the Technical University of Lisbon.

\section{References}

J.M. Aldric, P. Thonart

Performance evaluation of a water/silicone oil two-phase partitioning bioreactor using Rhodococcus erythropolis T902.1 to remove volatile organic compounds from gaseous effluents

J. Chem. Technol. Biotechnol., 83 (2008), pp. 1401-1408

J.M. Aldric, S. Gillet, F. Delvigne, P. Thonart

Development of an original approach to evaluate effect of surfactants, biomass and pollutants on the scaling-up of a two-phase partitioning bioreactor

J. Chem. Technol. Biotechnol., 85 (2010), pp. 356-363

S. Arriaga, R. Muñoz, S. Hernández, B. Guieysse, S. Revah

Gaseous hexane biodegradation by Fusarium solani in two liquid phase packed-bed and stirred-tank bioreactors

Environ. Sci. Technol., 40 (2006), pp. 2390-2395

L. Bailón, M. Nikolausz, M. Kästner, M.C. Veiga, C. Kennes

Removal of dichloromethane from waste gases in one- and two- liquid-phase stirred tank bioreactors and biotrickling filters

Water Res., 43 (2009), pp. 11-20

D. Bir

Partition coefficient calculation of selected terpenes and low molecular weight solvents between tall oil fatty acid and air and polydimethyl siloxane oil and air

J. Am. Oil Chem. Soc., 77 (2000), pp. 163-169

N.G. Boudreau, A.J. Daugulis

Transient performance of two-phase partitioning bioreactors treating a toluene contaminated gas stream

Biotechnol. Bioeng., 94 (2006), pp. 448-457

S.B. Corchnoy, R. Atkinson

Kinetics of the gas-phase reactions of $\mathrm{OH}$ and $\mathrm{NO}_{3}$ radicals with 2-carene, 1,8-cineole, p-cymene and terpinolene

Environ. Sci. Technol., 24 (1990), pp. 1497-1502 
G. Darracq, A. Couvert, C. Couriol, A. Amrane, D. Thomas, E. Dumont, Y. Andres, P. Le Cloirec

Silicone oil: an effective absorbent for the removal of hydrophobic volatile organic compounds

J. Chem. Technol. Biotechnol., 85 (2010), pp. 309-313

G. Darracq, A. Couvert, C. Couriol, A. Amrane, D. Thomas, E. Dumont, Y. Andres, P. Le Cloirec

Silicone oil: an effective absorbent for the removal of hydrophobic volatile organic compounds

J. Chem. Technol. Biotechnol., 86 (2010), p. 324 (Erratum)

C.T. Davidson, A.J. Daugulis

The treatment of gaseous benzene by two-phase partitioning bioreactor: a high performance alternative to use of biofilters

Appl. Microbiol. Biotechnol., 62 (2003), pp. 297-301

C.T. Davidson, A.J. Daugulis

Addressing biofilter limitations: a two-phase partitioning bioreactor process for the treatment of benzene and toluene contaminated gas streams

Biodegradation, 14 (2003), pp. 415-421

E. Déziel, Y. Comeau, R. Villemur

Two-liquid-phase bioreactor for enhanced degradation of hydrophobic/toxic compounds Biodegradation, 10 (1999), pp. 219-233

R.M.M. Diks, S.P.P. Ottengraf, S. Vrijland

The existence of a biological equilibrium in a trickling filter for waste gas purification Biotechnol. Bioeng., 44 (1994), pp. 1279-1287

E. Dumont, Y. Andrès, P. Le Cloirec

Mass transfer coefficient of styrene and oxygen into silicone oil emulsions in a bubble reactor

Chem. Eng. Sci., 61 (2006), pp. 5612-5619

A. Falk, E. Gullstrand, A. Löf, E. Wigaeus-Hjelm

Liquid/air partition coefficients of four terpenes

Br. J. Ind. Med., 47 (1990), pp. 62-64

Y. Fang, R. Govind

$\mathrm{CO}_{2}$ response to doses of organic solvents biodegraded in a batch biofilter

Water Air Soil Pollut., 175 (2006), pp. 33-48

Gruber, D.F., 2007. Ecological stoichiometry of marine bacteria: relationship to growth rate, protozoan predation, and organic matter degradation. Ph.D. thesis. The State University of New Jersey 
P. Hejazi, F. Borenberg, G. Işik, K. Rupar-Gadd, G. Strandmark, S.A. Shojaosadati, U. Welander

Treatment of $\alpha$-pinene-contaminated air using silicone oil-coated perlite biofilter

Environ. Prog. Sustain. Energy, 29 (2010), pp. 313-318

B.S. Hernandez, S.-C. Koh, M. Chial, D.D. Focht

Terpene-utilizing isolates and their relevance to enhanced biotransformation of polychlorinated biphenyls in soils

Biodegradation, 8 (1997), pp. 153-158

M. Hernández, G. Quijano, F. Thalasso, A.J. Daugulis, S. Villaverde, R. Muñoz

A comparative study of solid and liquid non-aqueous phases for the biodegradation of hexane in two-phase partitioning bioreactors

Biotechnol. Bioeng., 106 (2010), pp. 731-740

Y. Jin, M.C. Veiga, C. Kennes

Performance optimization of the fungal biodegradation of $\alpha$-pinene in gas-phase biofilter

Process Biochem., 41 (2006), pp. 1722-1728

Y. Jin, L. Guo, M.C. Veiga, C. Kennes

Fungal biofiltration of $\alpha$-pinene: effects of temperature, relative humidity and transient loads

Biotechnol. Bioeng., 96 (2007), pp. 433-443

C. Kennes, M.C. Veiga

Bioreactors for Waste Gas Treatment

Kluwer Academic Publishers, Dordrecht, Boston (2001)

C. Kennes, M. Montes, M.E. López, M.C. Veiga

Waste gas treatment in bioreactors: environmental engineering aspects

Can. J. Civil Eng., 36 (2009), pp. 1887-1894

C. Kennes, E.R. Rene, M.C. Veiga

Bioprocesses for air pollution control

J. Chem. Technol. Biotechnol., 84 (2009), pp. 1419-1436

G.T. Kleinheinz, S.T. Bagley, W.P. St John, J.R. Rughani, G.D. McGinnis

Characterisation of alpha-pinene degrading microorganisms and application to a benchscale biofiltration system for VOC degradation

Arch. Environ. Contam. Toxicol., 37 (1999), pp. 151-157

Z. Kong, L. Farhana, R.R. Fulthorpe, D.G. Allen

Treatment of volatile organic compounds in a biotrickling filter under thermophilic conditions

Environ. Sci. Technol., 35 (2001), pp. 4347-4352

B.M. Langolf, G.T. Kleinheinz

A lava rock-based biofilters for the treatment of alpha-pinene

Bioresour. Technol., 97 (2006), pp. 1951-1958 
J. Marcoux, E. Déziel, R. Villemur, F. Lépine, J.G. Bisaillon, R. Beaudet

Optimization of high-molecular-weight polycyclic aromatic hydrocarbons' degradation in a two-liquid-phase bioreactor

J. Appl. Microbiol., 88 (2000), pp. 655-662

B.T. Mohammad, M.C. Veiga, C. Kennes

Mesophilic and thermophilic biotreatment of BTEX-polluted air in reactors

Biotechnol. Bioeng., 97 (2007), pp. 1423-1438

M. Mohseni, D.G. Allen

Biofiltration of mixtures of hydrophilic and hydrophobic volatile organic compounds

Chem. Eng. Sci., 55 (2000), pp. 1545-1558

M. Montes, M.C. Veiga, C. Kennes

Two-liquid-phase mesophilic and thermophilic biotrickling filters for the biodegradation of $\alpha$-pinene

Bioresour. Technol., 101 (2010), pp. 9493-9499

M. Montes, A.J. Daugulis, M.C. Veiga, C. Kennes

Characterization of absorbent polymers for the removal of volatile hydrophobic pollutants from air

J. Chem. Technol. Biotechnol., 86 (2011), pp. 47-53

J.L.E. Morrish, E.T. Brennan, H.C. Dry, A.J. Daugulis

Enhanced bioproduction of carvone in a two-liquid-phase partitioning bioreactor with a highly hydrophobic biocatalyst

Biotechnol. Bioeng., 101 (2008), pp. 768-775

R. Muñoz, S. Arriaga, S. Hernández, B. Guieysse, S. Revah

Enhanced hexane biodegradation in a two phase partitioning bioreactor: overcoming pollutant transport limitations

Process Biochem., 41 (2006), pp. 1614-1619

R. Muñoz, S. Villarverde, B. Guieysse, S. Revah

Two-phase partitioning bioreactors for treatment of volatile organic compounds

Biotechnol. Adv., 25 (2007), pp. 410-422

R. Muñoz, M. Chambaud, S. Bordel, S. Villaverde

A systematic selection of the non-aqueous phase in a bacterial two liquid phase bioreactor treating $\alpha$-pinene

Appl. Microbiol. Biotechnol., 79 (2008), pp. 33-41

D. Nielsen, A.J. Daugulis, P.J. McLellan

Quantifying maintenance requirements from the steady-state operation of a two-phase partitioning

Bioscrubber, 90 (2005), pp. 248-258

L. Peeva, S. Ben-zvi Yona, J.C. Merchuk

Mass transfer coefficients of decane to emulsions in a bubble columns reactor

Chem. Eng. Sci., 56 (2001), pp. 5201-5206 
G. Quijano, M. Hernández, S. Villaverde, F. Thalasso, R. Muñoz

A step-forward in the characterization and potential applications of solid and liquid oxygen transfer vectors

Appl. Microbiol. Biotechnol., 85 (2010), pp. 543-551

E.R. Rene, R. Špačková, M.C. Veiga, C. Kennes

Biofiltration of mixtures of gas-phase styrene and acetone with the fungus Sporothrix variecibatus

J. Hazard. Mater., 184 (2010), pp. 204-214

E.R. Rene, M. Montes, M.C. Veiga, C. Kennes

Styrene removal from polluted air in one and two-liquid phase biotrickling filter: steady and transient-stage performance and pressure drop control

Bioresour. Technol., 102 (2011), pp. 6791-6800

E.R. Rene, M.C. Veiga, C. Kennes

Performance evaluation and neural modeling of gas-phase styrene removal in one- and two-liquid phase suspended-growth bioreactors

Ind. Eng. Chem. Res., 50 (2011), pp. 6485-6495

J. Rocha-Rios, S. Bordel, S. Hernández, S. Revah

Methane degradation in two-phase partition bioreactors

Chem. Eng. J., 152 (2009), pp. 289-292

J. Rocha-Rios, R. Muñoz, S. Revah

Effect of silicone oil fraction and stirring rate on methane degradation in a stirred tank reactor

J. Chem. Technol. Biotechnol., 85 (2010), pp. 314-319

J.W. van Groenestijn, J.X. Liu

Removal of alpha-pinene from gases using biofilters containing fungi

Atmos. Environ., 36 (2002), pp. 5501-5508 